\title{
SOCIAL SUPPORT AMONG VIETNAMESE UNIVERSITY STUDENTS: EVIDENCE OF GENDER DIFFERENCES
}

\author{
Ho Thi Truc Quynh ${ }^{a, b^{*}}$ \\ ${ }^{a}$ School of Psychology, Central China Normal University, Wuhan, China \\ ${ }^{b}$ Department of Psychology and Education, Hue University of Education, Thua Thien Hue, Vietnam \\ *Correspondence author: E-mail: hothitrucquynh@gmail.com \\ Article history \\ Received: October $4^{\text {th }}, 2020$ \\ Received in revised form: January $11^{\text {th }}, 2021 \mid$ Accepted: January $18^{\text {th }}, 2021$ \\ Available online: May $11^{\text {th }}, 2021$

\begin{abstract}
Social support is considered to be an important element of relationships. Previous studies have provided evidence that low social support is closely related to poor physical and mental health. Gender has an important influence on social support for university students; however, research on the level of social support and differences in social support by gender for Vietnamese university students is still lacking. The current study aims to investigate the level of social support and gender differences in social support for Vietnamese university students. A total of 859 Vietnamese university students have completed the Perceived Social Support Scale (PSSS). The results revealed that Vietnamese university students have a high level of social support and that male students have a lower level of social support than female students. Factors that may contribute to gender differences in social support are discussed. These findings have important implications for the development of interventions to provide gender-based social support.
\end{abstract}

Keywords: Gender difference; Social support; University students; Vietnamese students.

DOI: http://dx.doi.org/10.37569/DalatUniversity.12.1.777(2022)

Article type: (peer-reviewed) Full-length research article

Copyright () 2021 The author(s).

Licensing: This article is licensed under a CC BY-NC 4.0 


\section{INTRODUCTION}

Social support is considered to be an important element of relationships (Virtanen \& Isotalus, 2012); it is the individual's belief that they will receive help when needed (Sarason et al., 1991). In a number of studies, low social support has been closely linked to psychological distress and mental disorders (Peirce et al., 2000; Stansfeld et al., 1998; Zimet et al., 1988), low self-esteem (Chang et al., 2018; Li et al., 2018), and depression symptoms (Cohen \& Wills, 1985; Noteboom et al., 2016). Therefore, social support is often considered a protective factor for an individual's mental health.

According to Maheswari and Maheswari (2016), the university years are a period in which most students develop their sense of identity. For many university students, this is also the first time away from family and relatives to explore university life and discover themselves. Living in a new environment, university students strive to make friends and need to be accepted by them. Social support is essential at this time. It is a common observation that individuals with low social support often report a higher risk of depression (Chang et al., 2018; Ho et al., 2020; Noteboom et al., 2016).

Gender is an important predictor of social support, although studies have often overlooked gender differences in social support (Matud et al., 2003). The literature on gender differences in social support is somewhat inconsistent (Soman et al., 2016). In particular, Barnett et al. (2020) found no gender differences in the level of social support. However, most studies have reported that gender is significantly correlated with social support (Koydemir-Özden, 2010; Kugbey et al., 2015; Neff \& Karney, 2005; Reevy et al., 2001; Siddiqui et al., 2019; Tahmasbipour \& Taheri, 2012; Tayfur \& Ulupinar, 2016). Specifically, men have lower levels of social support than women (Gökçearslan et al., 2018; Kugbey et al., 2015; Tahmasbipour \& Taheri, 2012; Tayfur \& Ulupinar, 2016). To explain this gender difference, researchers have focused on gender socialization and gender identity. Female characteristics include being warm, supportive, compassionate, sensitive to the feelings of others, and expressing emotions. In contrast, males often focus on independence, competition, and self-reliance, rather than on cultivating intimate and emotional aspects of social relationships (Reevy et al. , 2001).

In contrast, some studies found that in adolescents, females have less support from family and more support from friends than males (Cheng \& Chan, 2004). In adults, however, males reported higher levels of social support in most respects (Olson \& Shultz, 1994). In this study, we expect that male students have lower levels of social support than female students.

Understanding gender differences in social support is important in the development of intervention strategies that improve social support for individuals. Previous studies involving university students have found gender differences in social support (Gökçearslan et al., 2018; Kugbey et al., 2015; Tayfur \& Ulupinar, 2016). In Vietnam, research has been conducted on social support for university students (Đinh \& Nguyễn, 2010; Ho et al., 2020). However, there is a lack of research on gender differences 
in social support among Vietnamese university students. The present study aims to fill this gap.

Based on previous studies, the following hypotheses are proposed in this study:

- Hypothesis 1: Vietnamese university students have high levels of social support.

- Hypothesis 2: Male Vietnamese university students have lower levels of social support than female students.

\section{METHODS}

\subsection{Sample}

A total of 859 Vietnamese university students (351 males and 508 females, including 272 second-year students, 311 third-year students, and 276 fourth-year students) have completed the Vietnamese version of the Perceived Social Support Scale (PSSS) and demographic information. The participants had a mean age of 20.74 years $(S D=1.12)$. The study has been approved by the school's leadership. All students have signed a consent form to voluntarily participate in the study.

\subsection{Measurements}

The Vietnamese version of the Perceived Social Support Scale (Đinh \& Nguyễn, 2010) was developed from the Perceived Social Support Scale (PSSS) (Zimet et al., 1988) and used to measure the level of social support among Vietnamese university students. The PSSS includes 12 items representing three dimensions of social support (a four-item parental support subscale, a four-item peer support subscale, and a four-item special person support subscale). The items were answered on a five-point Likert scale ranging from very strongly disagree to very strongly agree (0-4). Sample items include "I get the emotional help and support I need from my family," "My friends really try to help me," and "There is a special person in my life who cares about my feelings." Social support scores ranged from 0 to 48 with a higher overall score indicating a higher level of social support. The reliability and validity of this scale in the sample of Vietnamese university students has been confirmed (Đinh \& Nguyễn, 2010; Ho et al., 2020). In this study, the PSSS has good reliability: parental support subscale $(\alpha=0.902)$, peer support subscale $(\alpha=0.900)$ and special person support subscale $(\alpha=0.918)$. Information on gender, age, and grade level was collected at the end of the questionnaire.

\subsection{Data analysis}

Descriptive statistics that were calculated include the mean and standard deviation of social support resources for Vietnamese university students. Independent $t$-tests were used to identify gender differences in social support. Effect size was described using Cohen's $d$, where 0.20 constitutes a small effect, 0.50 a medium effect, and 0.80 a large effect (Cohen, 1988). Statistical analyses were performed using SPSS v.20. 


\section{RESULTS}

As shown in Table 1 and Figure 1, the social support score for Vietnamese students was $31.57(S D=14.58)$. Support scores from parents $(M=11.11, S D=5.27)$ were higher than support scores from peers $(M=9.78, S D=5.24)$ and special persons $(M=10.67, S D=5.18)$.

Table 1. Social support for Vietnamese university students

\begin{tabular}{lll}
\hline & Mean & $S D$ \\
\hline Total social support & 31.57 & 14.58 \\
Parental support & 11.11 & 5.27 \\
Peer support & 9.78 & 5.24 \\
Support by others & 10.67 & 5.18 \\
\hline
\end{tabular}

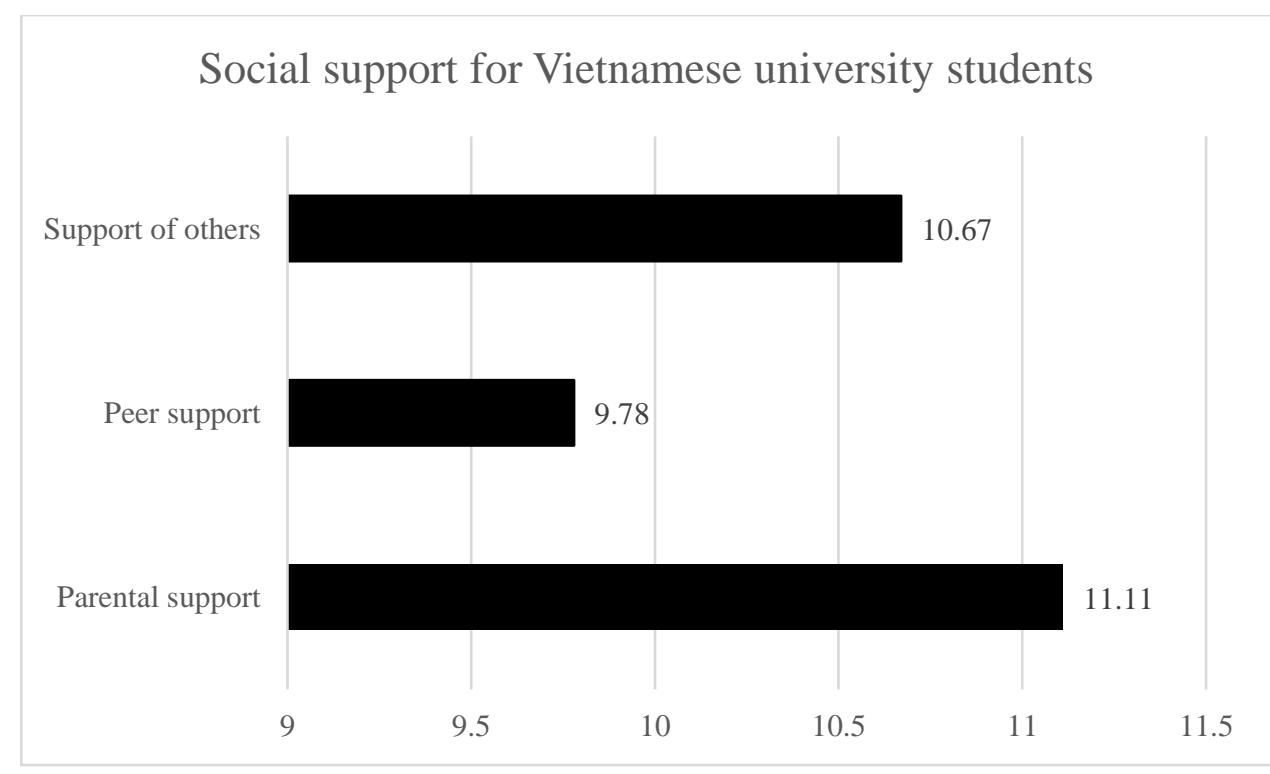

Figure 1. Social support for Vietnamese university students

To test Hypothesis 2, an independent $t$-test was used. The results showed that, in general, male students had a lower level of social support than female students (Figure 2 and Table 2). Specifically, the parental support scores of male and female students were $9.47(S D=5.11)$ and $12.25(S D=5.08)$, respectively; female students received more parental support than male students $\left(t_{(857)}=-7.88, p<0.001\right.$, Cohen's $d=0.54-$ a medium size effect). The peer support scores of male and female students were $8.26(S D=5.23)$ and $10.84(S D=4.98)$, respectively; female students received more peer support than male students $\left(t_{(857)}=-7.31, p<0.001\right.$, Cohen's $d=0.51-$ a medium size effect $)$. The special person support scores of male and female students were $9.03(S D=5.06)$ and $11.80(S D=4.95)$, respectively; female students received more special person support 
than male students $\left(t_{(857)}=-8.00, p<0.001\right.$, Cohen's $d=0.55-$ a medium size effect) (see Table 2).

\section{Table 2. Differences in the level of social support between males and females}

\begin{tabular}{lllllll}
\hline Social support & Variables & $M$ & $S D$ & $t_{(857)}$ & $p$ & $d$ \\
\hline Parental & Female & 12.25 & 5.08 & -7.88 & $<0.001$ & 0.54 \\
& Male & 9.47 & 5.11 & & & \\
Peer & Female & 10.84 & 4.98 & -7.31 & $<0.001$ & 0.51 \\
& Male & 8.26 & 5.23 & & & \\
Special person & Female & 11.80 & 4.95 & -8.00 & $<0.001$ & 0.55 \\
& Male & 9.03 & 5.06 & & & \\
\hline
\end{tabular}

\section{Differences in the level of social support between males and females}

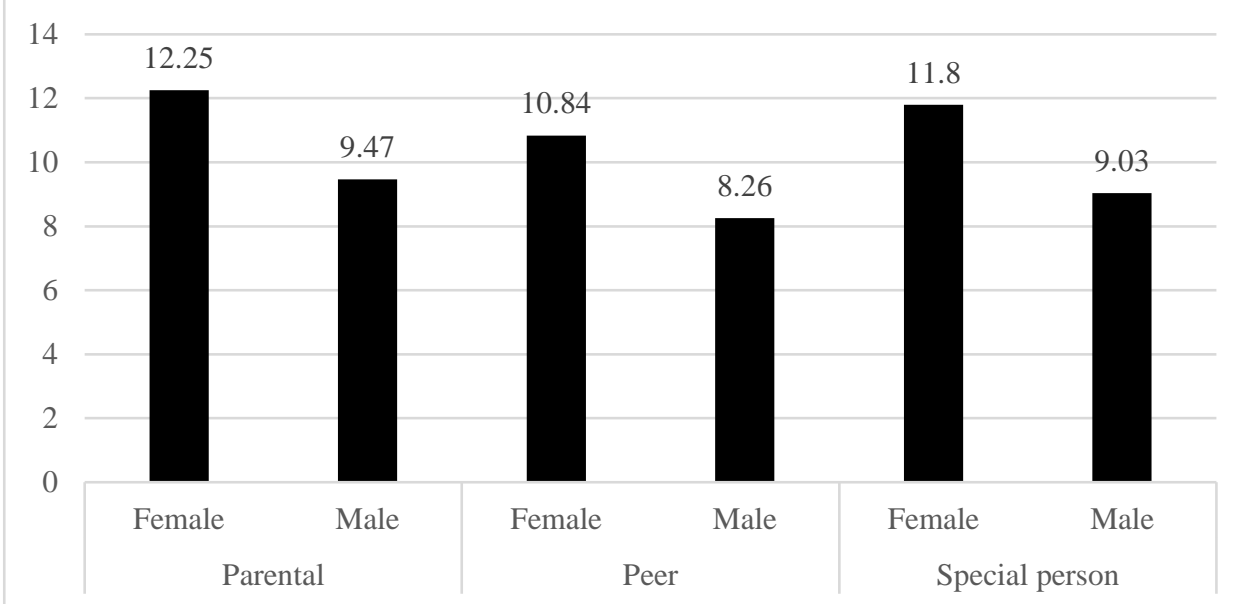

Figure 2. Gender differences in social support for Vietnamese university students

\section{DISCUSSION}

Consistent with the findings of Đinh and Nguyễn (2010), Jun et al. (2018), and Karaca et al. (2019), Vietnamese university students have relatively high levels of social support, which supports Hypothesis 1 . This may be because Vietnam is a country with a high level of community culture and high personal cohesion (Đinh \& Nguyễn, 2010). Consistent with previous studies, parental support was higher than other social support sources (Amato, 1993; Đinh \& Nguyễn, 2010). This is understandable because people are more likely to seek support from family than from friends and other acquaintances (Litwak \& Szelenyi, 1969).

We observed that male Vietnamese university students have a lower level of social support than female students, which supports Hypothesis 2. These results confirm 
previous findings on gender differences in social support (Gökçearslan et al., 2018; Kugbey et al., 2015; Tahmasbipour \& Taheri, 2012; Tayfur \& Ulupinar, 2016). Gender socialization and gender identity can be factors leading to gender differences in social support among Vietnamese university students. On the other hand, the ways in which men and women engage in social relationships are different (Belle, 1991). Cheng and Chan (2004), Hess et al. (2000), and Kendler et al. (2005) also explained that women tend to express themselves more emotionally and seek emotional support from those around them more than men. Wester et al. (2007) reported that men's social support networks are limited because seeking support or discussing emotions goes against male role expectations emphasizing strength and emotional restraint. According to Jackson (2011), men rarely seek help because they need to keep their masculine appearance. For many men, seeking help is often seen as the last resort because cultural expectations force men to try to solve all their problems on their own. Therefore, women are more likely to seek social support and have higher levels of social support than men.

\section{CONCLUSION}

Our research has revealed that Vietnamese university students have a high level of social support, with support from family higher than support from peers and other special people. This study has also shown that female Vietnamese university students have a higher level of social support than male students. The most important contribution of this study is the discovery of gender differences in social support among Vietnamese university students. These findings have important implications in the development of interventions to provide gender-based social support. However, like other studies, there are some limitations. The study used a self-reporting method, so the study results may depend on the participants' memories. Therefore, future studies should be conducted in combination with other methods to overcome the weaknesses of the self-reporting method.

\section{REFERENCES}

Amato, P. R. (1993). Urban-rural differences in helping friends and family members. Social Psychology Quarterly, 56(4), 249-262. https://doi.org/10.2307/2786662

Barnett, M. D., Maciel, I. V., Johnson, D. M., \& Ciepluch, I. (2020). Social anxiety and perceived social support: Gender differences and the mediating role of communication styles. Psychological Reports, 003329411990097.

Belle, D. (1991). Gender differences in the social moderators of stress. In Stress and coping: an anthology (pp. 257-277). Free Press.

Chang, C.-W., Yuan, R., \& Chen, J.-K. (2018). Social support and depression among Chinese adolescents: The mediating roles of self-esteem and self-efficacy. Children and Youth Services Review, 88, 128-134. https://doi.org/10.1016/j.childyouth. 2018.03.001 
Cheng, S. -T., \& Chan, A. C. M. (2004). The multidimensional scale of perceived social support: dimensionality and age and gender differences in adolescents. Personality and Individual Differences, 37(7), 1359-1369. https://doi.org/10.1016/j.paid.200 4.01.006

Cohen, J. (1988). Statistical power analysis for the behavioral sciences. Routledge Academic.

Cohen, S., \& Wills, T. A. (1985). Stress, social support, and the buffering hypothesis. Psychological Bulletin, 98(2), 310-357. https://doi.org/10.1037/0033-2909.98.2.310

Đinh, T. H. V., \& Nguyễn, P. C. T. (2010). Mối quan hệ giữa chố dựa xã hội và cách ứng phó của sinh viên trường Đại học $\mathrm{Y}$ Dược - Đại học Huế. Tạp chí Khoa học và Giáo duc, 1(13), 93-99.

Gökçearslan, Ş., Uluyol, Ç., \& Şahin, S. (2018). Smartphone addiction, cyberloafing, stress and social support among university students: A path analysis. Children and Youth Services Review, 91, 47-54. https://doi.org/10.1016/j.childyouth.2018.05.036

Hess, U., Senécal, S., Kirouac, G., Herrera, P., Philippot, P., \& Kleck, R. E. (2000). Emotional expressivity in men and women: Stereotypes and self-perceptions. Cognition \& Emotion, 14(5), 609-642. https://doi.org/10.1080/02699930050117648

Ho, T. T. Q., Li, C., \& Gu, C. (2020). Cyberbullying victimization and depressive symptoms in Vietnamese university students: Examining social support as a mediator. International Journal of Law, Crime and Justice, 63, 100422. https://doi.org/10.1016/j.ijlcj.2020.100422

Jackson. (2011). Gender differences in seeking help [Master thesis, Eastern Kentucky University].

Jun, W. H., Yang, J., \& Lee, E. J. (2018). The mediating effects of social support and a grateful disposition on the relationship between life stress and anger in Korean nursing students. Asian Nursing Research, 12(3), 197-202. https://doi.org/10.1016/ j.anr.2018.08.002

Karaca, A., Yildirim, N., Cangur, S., Acikgoz, F., \& Akkus, D. (2019). Relationship between mental health of nursing students and coping, self-esteem and social support. Nurse Education Today, 76, 44-50. https://doi.org/10.1016/j.nedt.2019 .01 .029

Kendler, K. S., Myers, J., \& Prescott, C. A. (2005). Sex differences in the relationship between social support and risk for major depression: A longitudinal study of opposite-sex twin pairs. American Journal of Psychiatry, 162(2), 250-256. https://doi.org/10.1176/appi.ajp.162.2.250

Koydemir-Özden, S. (2010). Self-aspects, perceived social support, gender, and 
willingness to seek psychological help. International Journal of Mental Health, 39(3), 44-60. https://doi.org/10.2753/IMH0020-7411390303

Kugbey, N., Osei-Boadi, S., \& Atefoe, E. A. (2015). The influence of social support on the levels of depression, anxiety and stress among students in ghana the influence of social support on the levels of depression. Journal of Education and Practice, 6(25), 135-140.

Li, J., Han, X., Wang, W., Sun, G., \& Cheng, Z. (2018). How social support influences university students' academic achievement and emotional exhaustion: The mediating role of self-esteem. Learning and Individual Differences, 61, 120-126. https://doi.org/10.1016/j.lindif.2017.11.016

Litwak, E., \& Szelenyi, I. (1969). Primary group structures and their functions: Kin, neighbors, and friends. American Sociological Review, 34(4), 465-481. https://doi.org/10.2307/2091957

Maheswari, R., \& Maheswari. K. (2016). A study on self-esteem among the college students. IOSR Journal of Humanities And Social Science, 21(10), 8-10. https://doi.org/10.9790/0837-2109122124

Matud, M. P., Ibáñez, I., Bethencourt, J. M., Marrero, R., \& Carballeira, M. (2003). Structural gender differences in perceived social support. Personality and Individual Differences, 35(8), 1919-1929. https://doi.org/10.1016/S0191-8869(03)00041-2

Neff, L. A., \& Karney, B. R. (2005). Gender differences in social support: A question of skill or responsiveness? Journal of Personality and Social Psychology, 88(1), 7990. https://doi.org/10.1037/0022-3514.88.1.79

Noteboom, A., Beekman, A. T. F., Vogelzangs, N., \& Penninx, B. W. J. H. (2016). Personality and social support as predictors of first and recurrent episodes of depression. Journal of Affective Disorders, 190, 156-161. https://doi.org/10.10 16/j.jad.2015.09.020

Olson, D. A., \& Shultz, K. S. (1994). Gender differences in the dimensionality of social support. Journal of Applied Social Psychology, 24(14), 1221-1232. https://doi.org/ 10.1111/j.1559-1816.1994.tb00555.x

Peirce, R. S., Frone, M. R., Russell, M., Cooper, M. L., \& Mudar, P. (2000). A longitudinal model of social contact, social support, depression, and alcohol use. Health Psychology, 19(1), 28-38. https://doi.org/10.1037/0278-6133.19.1.28

Reevy, G. M., Bay, E., \& Maslach, C. (2001). Use of social support: Gender and personality differences. Sex Roles: A Journal of Research, 44, 437-459. https://doi.org/10.1023/A:1011930128829

Sarason, B. R., Pierce, G. R., Shearin, E. N., Sarason, I. G., \& et al. (1991). Perceived 
social support and working models of self and actual others. Journal of Personality and Social Psychology, 60(2), 273-287. https://doi.org/10.1037/0022-3514.60.2.273

Siddiqui, R. S., Jahangir, A. A., \& Hassan, A. (2019). Gender differences on perceived social support and psychological distress among university students. Global Management Journal for Academic \& Corporate Studies, 9(2), 210-223.

Soman, S., Bhat, S. M., Latha, K. S., \& Praharaj, S. K. (2016). Gender differences in perceived social support and stressful life events in depressed patients. East Asian Archives of Psychiatry, 26(1), 22-29.

Stansfeld, S. A., Fuhrer, R., \& Shipley, M. J. (1998). Types of social support as predictors of psychiatric morbidity in a cohort of British Civil Servants (Whitehall II Study). Psychological Medicine, 28(4), 881-892. https://doi.org/10.1017/S0033291798006746

Tahmasbipour, N., \& Taheri, A. (2012). A survey on the relation between social support and mental health in students Shahid Rajaee University. Procedia - Social and Behavioral Sciences, 47, 5-9. https://doi.org/10.1016/j.sbspro.2012.06.603

Tayfur, C, \& Ulupinar, S. (2016). The effect of perceived social support on the academic achievement of health college students. Journal of Psychiatric Nursing, 7(1), 1-6. https://doi.org/10.5505/phd.2016.52523

Virtanen, I. A., \& Isotalus, P. (2012). The essence of social support in interpersonal communication. Empedocles: European Journal for the Philosophy of Communication, 3(1), 25-42. https://doi.org/10.1386/ejpc.3.1.25_1

Wester, S. R., Christianson, H. F., Vogel, D. L., \& Wei, M. (2007). Gender role conflict and psychological distress: The role of social support. Psychology of Men \& Masculinity, 8(4), 215-224. https://doi.org/10.1037/1524-9220.8.4.215

Zimet, G. D., Dahlem, N. W., Zimet, S. G., \& Farley, G. K. (1988). The multidimensional scale of perceived social support. Journal of Personality Assessment, 52(1), 30-41. https://doi.org/10.1207/s15327752jpa5201_2 